\title{
Think Aloud Analysis of Probability Word Problems among College Students
}

\author{
Mardiana Yusuf ${ }^{1 *}$ and Suzieleeze Serene Abdul Rahim ${ }^{1}$ \\ ${ }^{1}$ Faculty of Education, University Malaya, Malaysia
}

\begin{abstract}
This study explores the strategies used in solving probability word problems by a college student. Problem solving with various ways of solutions was a bit complicated for students in need to choose the best strategy to solve them. Thinking aloud used as an analysis tool to evaluate the influence thought and behaviour of the participants in the study during solving seven tasks. Three participants were chosen as a preliminary of a case study. An in-depth semi-structured interview was conducted together with the think-aloud analysis to gain rich and thick descriptions from the participants. Protocols were coded and analyzed to determine what strategies they used and why they choose those strategies to solve the problems. Results indicated that participants loved to use visual representations as strategies in solving probability problems such as basic diagrams and sketches without knowing the accuracy of its effect.
\end{abstract}

Keywords: strategy, problem solving, probability, think-aloud

\section{Introduction}

Probability is a tough concept. When asked about the probability of occurrence, many students think that they are asked to predict whether the event will occur, rather than suppose they measure how likely, or often it will be. The probability is not about predicting whether a particular event will take place but about determining how the probability is propagated over the possible events (Baltaci \& Evran, 2016; Beitzel, Stally, \& DuBois, 2011; Galavotti, 2015). Not only the students, but adults also face problems to think about the probability and disability. If this continues, the student cannot control the probability that involves a daily situation of decisions and judgments, for example when assessing risk (Batanero, Chernoff, Engel, Lee, \& Sánchez, 2016).

Although the probability is slowly infiltrating into the mathematical curriculum, it is still not considered a necessary topic in it and is considered a topic at the end of the text of the book that will be protected if there is time. Continuous research has given high awareness of the probability requirements not only in class mathematics but also in physical, biological and social sciences (Jones, 2005). Now, the probability requirements are emphasized in mathematics and curriculum by introducing several concepts of probability across curriculum schools (NCTM, 2010).

The probability is a mathematical branch with broad forecasts in science, business and industry research, politics and everyday life (Bamberger, 2003) making it a subject that must be learned by all science and technology students, social sciences and businesses at Matriculation College in Malaysia (Bahagian Matrikulasi, 2018). Feedback of some mathematics lecturers at the matriculation colleges, although secondary students have learned the probability and the two-year topics at the secondary level, they still cannot solve the probability of event properly and correctly. According to them, many students did not know the use of the probability problem solving strategies previously learned. This statement is supported by (Danisman \& Tanisli, 2017) stating that average teachers and middle-aged lecturers think that students should be aware of the basic concepts because of the introduction to the probabilities taught in previous years, but because of the lack of knowledge of vertical curriculum, they cannot ensure the students' existing knowledge about probabilities.

Extensive exploration of the concept of probability in the curriculum requires further research on the probability of thinking among students of all ages. Although there are studies on student thinking in probability (Ang \& 
Shahrill Masitah, 2014; Baltaci \& Evran, 2016; Batanero \& Sanchez, 2013; Borovcnik, 2012) little research on student thinking in the classroom (Diaz \& Batanero, 2009; Tan \& Tan, 2015), and still lack research focused on learning and teaching probabilities at college level (Corter \& Zahner, 2007; Effandi Zakaria \& Normah Yusoff, 2009).

Focusing on the concept of probabilities and events in the classroom, this study aims to explore the strategy used by matriculation college students to solve probability problems with various forms of solutions. The objective of this research is to identify what are the favourite methods used by the student in solving probability word problems as they have known all of the solving strategies before. As one said, solving problems with various forms of settlement needs a wise action.

Therefore, the researchers wanted to answer about what methods do college students use to solve probability problems. Hence, this study should be implemented to contribute to the improvement of the quality of mathematics education in Malaysia.

\section{Methodology}

Participants. This research study took place at one of the matriculation colleges in Peninsula Malaysia. Approval from Matriculation Centre was received prior to commencing data collection. This study adopted a qualitative approach, which utilizes a case study. The participants were the volunteer to gain a rich, thick and indepth descriptions. They are two Malay females and one Indian boy with different academic variations participated in the study. Each participant was compensated with a gift for agreeing compensated in this study.

Procedure. The researcher provided the participants with seven tasks of the probability of event problems. Participants were asked to read each probability problem aloud before beginning the problem and to verbalize their thinking while attempting to solve the problems. Our research focusing on the problem solving strategies used by college students while dealing with the ambiguity of open-ended problems. Problems are used extensively in college curricula. Open-ended problems may have multiple possible solutions, although some may be more suitable than others. Jonassen (2000) stated that higher level mathematical solving problems are complex and have multiple paths to a solution.

Think aloud enables the researcher to identify the types of strategies used by problem solvers and how they are acquiring and using information during problem solving activities. Participants were encouraged to constantly speak out loud during they developed solutions to the problems and describe all their thoughts regardless of how inconsequential they may think they are to the process. Participants should reason aloud and verbalize every thought that comes to mind during the problem solving process. Researcher as the interviewer and the observer can also prompt participants at points when they may not be giving adequate details on their thought processes or during the extended period of silence.

Think aloud methods enables qualitative researchers to construct and collect data in 'real time'. Real data collection can provide a more accurate account of the 'real' (Aitken \& Mardegan, 2000). The proximity of the experience participants reflected in the data. The researcher can access the occurred phenomenon from various perspectives because the experience is being simultaneously lived by the participant and witnessed by the researcher.

This method of data collection was combined with video recordings of participants thinking aloud as well as retrospective interviews. Video recordings were made of each participant using camera positioned faced the participant focused on their work. From the videos, we can observe their behaviour or gesture during the 
interview. This is because spontaneous gestures influence strategy choices in problem solving (Alibali, Spencer, Knox, \& Kita, 2011). This absence of narrative linearity and coherence in some ways reflects an individual's thought processes when not being forced into expected scripts, desired outcomes, or cultural grand narratives.

Coding. Participants responses were classified in terms of problem solving strategies they expressed, taking both speech and behaviour. As participants read the text, they integrate text information with relevant prior knowledge to form a situation model. The generation of inferences is an integral component of constructing a coherent situation model. Therefore, to understand how they comprehend text, it is necessary to understand the inferences they make.

In that case, coding for this research was based on the solutions of the problems practically and verbally by the participants during they answered the tasks. All tapes were transcribed verbatim. The numbers of words were the effort expended by the participant while solving probability word problems. Therefore, the analysis was from the interview transcripts and the matching written uses of solution strategies in solving probability word problems.

\section{Results and Discussion}

This preliminary study shows that there are three methods used by participants during their task-based questions. We found out that the methods used are listing and constructing a diagram. The participants chose to used listing and constructing Venn diagram to solve probability event problems, while tree diagram to solved Independent event and conditional probability problems.

From this study, it reveals that in the problem solving-mathematics classroom, the students used all kinds of problem solving strategies to solve the problems. In addition, when the students solved the problems, they create their problem solving strategies. Thus, it could be considered that different students' ways of thinking support the students to use problem solving strategies variously (Intaros, Inprasitha, \& Srisawadi, 2014).

\section{Listing}

Although the method used is very simple, simply listing the information provided, but the student cannot do it properly. Analysis of think aloud indicates that they understand the question and can state the method to list correctly, but the information released into the sample set is incorrect. Even the mathematical procedure used was correct but still gives the wrong final answer.

For Sara, using listing beneficial for her as she gets the correct answer for a Dice Problem in getting the probability of one even and one odd number from the two dice that rolled at the same time. She knows the best method to use where her responses directly after reading the questions and solved it.

"One even number. One odd number. One two, one three, one five. Then the probability for even number and an odd number is three over six. So one over two."

However, Susen and Fazi also use method listing to solve the same problems but not succeed. This shows that the three participants used the same method to solve the problem but success does not belong to the knows. Maybe they need skills to enhance their knowledge even though they knew which method to use.

The set of numbers selection was done neatly using the listing method by the participants in a Wheel of Fortune Problem. The participants need to find the probability which can get a number either a perfect square or the sum of its digits is 7. To solve this problem, they need to know the mathematical concept before they do the process. Here are one of the participant responses and her work. 


\section{Student's response}

"Two square equal to 4 . Three square equal to nine. Four square equal to sixteen. Six square equal to thirty-six. Five square equal to twenty-five. Seven square... no lah.

So perfect square numbers have five over forty.

The probability is $\mathrm{P}$ (PS) equal to five over forty.

Then for SD seven... seven, sixteen, twenty-five, thirty-four.

So probability, P, SD Seven is four over forty.

Briefly, this is one over eight and this one, one over ten.

So, for this, the formula is, $\mathrm{P}$ (PS) and P (SD7) minus $P$ PS intersect SD7, so one over eight plus one over ten minus one over twenty.

The answer is seven over forty." (Fazi)
Student's work

$4,9,16,25,36$

$5 / 40$

$\mathrm{P}(\mathrm{PS})=5 / 40$

$\mathrm{SD} 7=7,16,25,34$

$\mathrm{P}(\mathrm{SD} 7)=4 / 40$

$\mathrm{P}(\mathrm{PS})=1 / 8, \mathrm{P}(\mathrm{SD} 7)=1 / 10$

$$
\begin{aligned}
& \mathrm{P}(\mathrm{PS} \cup \mathrm{SD} 7)=\mathrm{P}(\mathrm{PS})+\mathrm{P}(\mathrm{SD} 7)-\mathrm{P}(\mathrm{PS} \cap \mathrm{SD} 7) \\
& =1 / 8+1 / 10-1 / 20 \\
& =7 / 40
\end{aligned}
$$

However, matching the responses and the work, the perfect square listing process is incomplete. All of the participants do not list the correct numbers in set notation and missed numbers in the listing. According to the participants, they chose a listing strategy because the numbers given were small, that is 1 to 40 , can be kept on paper by calculating without using calculators. They can also state the process of calculation or steps are taken strongly and faithfully.

\section{Venn Diagram}

Selection for Venn diagram as a solution for probability event problem also the right choice for Newspaper Problem to find out the number of students that did not buy either two newspapers from their school store. This illustrates the students understand the keywords found in the problem. This strategy used gives a positive impact on the students by helping to develop a better and more permanent concept image (Gulkilik \& Arikan, 2012; Kurnaz \& Arslan, 2014). All the participants gave responses when asked why they chose this method to solve the question, although there are other methods they can use as a solution.

"And then thirty students are bought both NST and Star." (Susen)

"Who buys both is thirty." (Sara)

"If we make a Venn diagram near the same section there are thirty people." (Fazi)

However, the three of them get the wrong answer when entering the procedural path. In this study, we focused on the strategy or method used in solving probability word problem only, so we do not look at the misconception or right and wrong answers.

\section{Tree Diagram}

For the question of the independent event type, the method chosen by the participants to solve the problem is by using the tree diagram. The selection of the tree diagram method helps the participants to perform well which in turn contribute to the correct answer. The use of the tree diagram method can help them solve problems successfully.

Response from the participants shows that the choosing tree diagram can give them a direct answer to the Spinner Problem in getting the same colour on two spinners. This visual representation is often helpful in solving problems (Debrenti, 2015; Kurnaz \& Arslan, 2014). The participant responses during they construct the tree diagram. 
"Nine is the possible outcome. So one outcome divides by nine possible outcomes (finding the value on the tree diagram he draws). So probability to get the same colour is one over nine plus one over nine plus one over nine equal to three over nine." (Susen)

For this type of question, the procedure they used after constructing a tree diagram was explaining successfully. This situation explains the questions in parallel with the choice of the right solution method. The daily situation makes the participant choose the strategy spontaneously after reading the instructions without having to think about another strategy or hesitate to choose another strategy.

Basketball Problem is a daily life situation that was given to the participants to solve the problem of a young boy who wants to choose his jersey and short, both in blue colours. Real life situation also guides the participants to represent the problems in the mathematical form. The chosen strategy shows that visualize really help them to organize the data and help them in the calculation. Here is the feedback of a participant matching with his work.

\section{Student's response}

"There are four jerseys. Two orange and two blue. Break the jersey to two. Orange and blue. So to get the probability two orange is two over four. So the probability for blue is also two over four. So we want to match the jersey with the short pants. The short pants also have two colours. Blue and white. Blue, three over four and white, one over four. So for blue jersey, two over four and for blue pants three over four. So we can get three over eight. "(Fazi)

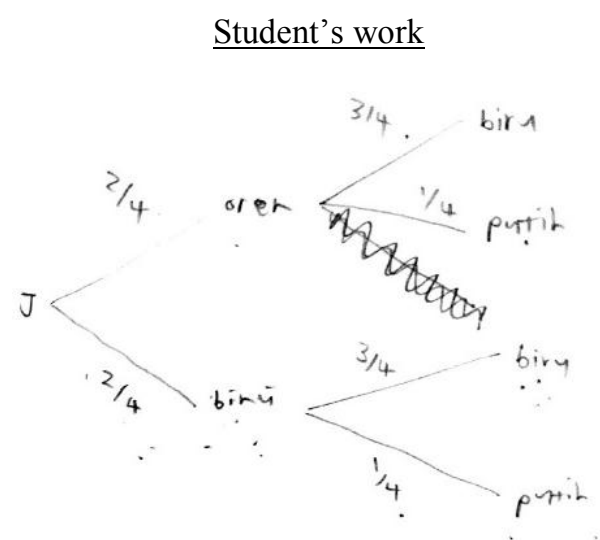

Conditional probability problem was one of the hardest tasks that are apparently more complex than others, in their data structure and in their solution complexity (Huerta, 2016). In this study, the selection of tree diagrams for problem solving is basically helpful to the students but if they do not know how to perform calculations, they would not succeed.

Based on the feedback, the participants were able to draw and label the tree diagram very well, but only one participant knows how to use the labels he has drawn to perform calculations correctly and accurately.

"Given the rain and no rain depicts this, then departs and does not depart for rain and does not rain (point to tree diagram drawn). So the probability of rain is zero point three so one minus zero point three equals to zero points seven for which does not rain. Departure is zero points one and not departing during rain is zero point nine. Depart on time is zero point eight for no rain, so depart not on time at no rain is zero point two. What is the probability of rain as the flight departs just in time? Ohh ... rain and depart on time (write formula on paper; $\mathrm{P}(\mathrm{R} \mid \mathrm{TO})=\mathrm{P}$ $(\mathrm{R} \cap \mathrm{TO})$ / $\mathrm{P}(\mathrm{TO})$ ). So $\mathrm{R}$ intersect departs on time, zero point one divide zero point three times zero point one plus zero point seven times zero point eight. So zero point one over zero point five nine equals to ten over fifty-nine." (Susen)

"Starting to say he has a chance of thirty per cent going to rain, so the probability of rain is zero point three. So if we want to find, do not rain, one minus zero point three can be zero points seven. Then, the question tells us, if the flight departs on time, so his opponent is not on time. So the probability of rain is broken into two directions (take a look at sketches on paper), one for on time and one for not on time. If on time there are zero points one and if not on time, one minus zero points one can be zero points nine. So if it does not rain, we break into two. Not rain but on 
time and one does not rain but he is not on time. So not to rain and on time has given that zero point eight so we minus to get on time that is one minus zero point eight can be zero points two, not to rain and not on time. So the answer is, zero point zero one five for the probability of rain, the flight departs on time." (Fazi)

From the responses, participants know how to read from the diagram they construct but they still wrongly calculated during the procedural mathematical forms. Incorrect values on each branch of the tree diagram can cause them to commit the wrong procedure.

Overall, students loved to imagine and use a tree diagram in all sorts of probability problems. Seems that for this question, they did not realize that conditional probability was different from other types of probability problems. Students need to memorize the formula for conditional probability even they know how to sketch and label the branches of the tree diagram correctly.

A basic diagram such as tree diagram and Venn diagram have the advantage of scientific and mathematical tasks. This also approved by Beitzel, Staley, and DuBois (2011) in their research where they found out tree diagram and Venn diagram effective as an aid in solving problems. Among the indicators that showed the students were unable to analyze when they solved mathematical problems was the students continued to answer the question by continuously making the calculation without delegating mathematical ideas (In'am, 2014; Krawec, 2014; Phonapichat, Wongwanich, \& Sujiva, 2014).

\section{Conclusion}

More than one participants used similar methods in solving probability word problems. We can conclude that college students used similar methods while dealing with the ambiguity of open-ended problem which they learned in math class even with different educators that teach them. Previous knowledge helped them a lot. From this study, we can assume that both parties, girls and boy interested in using visual diagrams such as tree diagram and Venn diagrams to represent their information given the problem as well as to find the value in doing the calculation to get the answers. This approved that visualization from imagery can help students solve problems even the student was not a visual person.

Instead, we learned from this preliminary study that the choice of strategies depends on many factors. But none of us knows what factors or what are the obstacles that students faced while solving probability word problems. There is no evidence that a particular strategy is more superior. Using the procedure to solve the hardest problems, constructing visual graphics with a tree diagram, Venn diagram or tables, or use formula that fixed for certain probability problems, but this finding just creates more synergies to the excitement in solving probability word problems.

To overcome this setback, our next study will justify the obstacles that are facing by these college students when solving probability word problems which they had learned over two to four years before they enter the undergraduate level. This study will be supported by participant observation and document analysis. Besides, the increasing participation in the study may overcome rich and more data that will be identified clearly what exactly the strategies used in solving probability word problems among college students.

\section{References}

Aitken, L. M., \& Mardegan, K. J. (2000). "Thinking aloud": data collection in the natural setting. Western Journal of Nursing Research, 22(7), 841-853. https://doi.org/10.1177/01939450022044791

Alibali, M. W., Spencer, R. C., Knox, L., \& Kita, S. (2011). Spontaneous gestures influence strategy choices in problem solving. Psychological Science, 22(9), 1138-1144. https://doi.org/10.1177/0956797611417722 
Ang, L. H., \& Shahrill Masitah. (2014). Identifying Students' Specific Misconceptions in Learning Probability. International Journal of Probability and Statistics, 3(2), 23-29. https://doi.org/10.5923/j.ijps.20140302.01

Bahagian Matrikulasi. (2018). Curriculum Specifications Mathematics 2 (DM025). Retrieved from http://1drv.ms/1D5ikaA\%5Cnmath/mathematics_2_1.djvu

Baltaci, S., \& Evran, A. (2016). Examination Of Gifted Students' Probability Problem Solving Process In Terms Of Mathematical Thinking. Malaysian Online Journal of Educational Technology, (4).

Bamberger, M. E. (2003). Methods College Students Use to Solve Probability Problems and the Factors that Support of Impede their Success. Oregon State University. https://doi.org/10.1024/1012-5302/a000034

Batanero, C., Chernoff, E. J., Engel, J., Lee, H. S., \& Sánchez, E. (2016). Research on Teaching and Learning Probability. The Proceedings of the 12th International Congress on Mathematical Education. https://doi.org/10.1007/978-3-319-31625-3_1

Batanero, C., \& Sanchez, E. (2013). What is the Nature of High School Students' Conceptions and Misconceptions About Probability? In Exploring probability in school: Challenges for teaching and learning (pp. 43-71). https://doi.org/10.1007/0-387-24530-8

Beitzel, B. D., Staley, R. K., \& DuBois, N. F. (2011). The (in)effectiveness of visual representations as an aid to solving probability word problems. Effective Education, 3(1), 11-22. https://doi.org/10.1080/19415532.2011.604256

Beitzel, B. D., Stally, R. K., \& DuBois, N. F. (2011). When Best Intentions Go Awry The Failures of Concrete Representations to Help Solve Probability Word Problems. Educational Research Quarterly, 34(3), 3-14. Retrieved from http://search.ebscohost.com/login.aspx?direct=true\&db=eax\&AN=59619869\&site=ehost-live

Borovcnik, M. (2012). Multiple perspectives on the concept of conditional probability. Avances de Investigación En Educación Matemática, (2), 5-27.

Corter, J. E., \& Zahner, D. C. (2007). Use of External Visual Representations in Probability Problem Solving. Statistics Education Research Journal.

Danisman, S., \& Tanisli, D. (2017). Examination of Mathematics Teachers' Pedagogical Content Knowledge of Probability. Malaysian Online Journal of Educational Sciences, 5(2), 16-34. Retrieved from http://libproxy.library.wmich.edu/login?url=https://search.proquest.com/docview/1913352728?accountid=1509 9

Debrenti, E. (2015). Visual Representations in Mathematics Teaching: an Experiment With Students. Acta Didactica Napocensia, 8(1), 1-15.

Diaz, C., \& Batanero, C. (2009). University Students' Knowledge and Biases in Conditional Probability Reasoning. International Electronic Journal of Mathematics Education, 4(3), 21-52. https://doi.org/10.1017/CBO9781107415324.004

Effandi Zakaria, \& Normah Yusoff. (2009). Attitudes and Problem-Solving Skills in Algebra Among Malaysian Matriculation College Students. European Journal of Social Sciences, Volume 8,(December), 232-245.

Galavotti, M. C. (2015). Probability Theories and Organization Science: The Nature and Usefulness of Different Ways of Treating Uncertainty. Journal of Management, 41(2), 744-760. https://doi.org/10.1177/0149206314532951

Gulkilik, H., \& Arikan, A. (2012). Preservice Secondary Mathematics Teacher's Views about Using Multiple Representations in Mathematics Instruction. Procedia - Social and Behavioral Sciences, 47(2006), 1751-1756. https://doi.org/10.1016/j.sbspro.2012.06.895

Huerta, M. P. (2016). Researching Conditional Probability Problem Solving, (January 2014). https://doi.org/10.1007/978-94-007-7155-0

In'am, A. (2014). The implementation of the Polya method in solving Euclidean geometry problems. International Education Studies, 7(7), 149-158. https://doi.org/10.5539/ies.v7n7p149

Intaros, P., Inprasitha, M., \& Srisawadi, N. (2014). Students' Problem Solving Strategies in Problem Solvingmathematics Classroom. Procedia - Social and Behavioral Sciences, 116, $4119-4123$. https://doi.org/10.1016/j.sbspro.2014.01.901 
Jonassen, D. H. (2000). Toward a design theory of problem solving. Educational Technology Research and Development, 48(4), 63-85. https://doi.org/10.1007/BF02300500

Krawec, J. L. (2014). Problem Representation and Mathematical Problem Solving of Students of Varying Math Ability. Journal of Learning Disabilities, 47(2), 103-115. https://doi.org/10.1177/0022219412436976

Kurnaz, M. A., \& Arslan, A. S. (2014). Effectiveness of Multiple Representations for Learning Energy Concepts: Case of Turkey. Procedia - Social and Behavioral Sciences, 116, 627-632. https://doi.org/10.1016/j.sbspro.2014.01.269

NCTM. (2010). Why is Teaching with Problem Solving Important to Student Learning? National Council of Teachers of Mathematics, 13(12), 1-6. https://doi.org/10.1016/S2213-8587(14)70016-6

Phonapichat, P., Wongwanich, S., \& Sujiva, S. (2014). An Analysis of Elementary School Students' Difficulties in Mathematical Problem Solving. Procedia - Social and Behavioral Sciences, 116(2012), 3169-3174. https://doi.org/10.1016/j.sbspro.2014.01.728

Tan, C.-K., \& Tan, C.-P. (2015). Teaching Probability With Graphic Calculator Instructional Approach. The Journal of Developing Areas, 49(5), 11-23. Retrieved from https://search.proquest.com/docview/1707487514?accountid=10673\%0Ahttp://openurl.ac.uk/redirect/athens:edu /?url_ver=Z39.88-

2004\&rft_val_fmt=info:ofi/fmt:kev:mtx:journal\&genre=article\&sid=ProQ:ProQ\%3Aabiglobal\&atitle=TEACHI NG+PROBABILITY+WITH+GRAPHIC+CALCUL 